\title{
Income convergence: fresh evidence from the Nordic countries
}

\author{
Venus Khim-Sen Liew ${ }^{\mathrm{a}, *}$ and Yusuf Ahmad $^{\mathrm{b}}$ \\ ${ }^{a}$ Labuan School of International Business and Finance, Universiti Malaysia \\ Sabah, Jalan Sungai Pagar, 87000 Labuan, Malaysia \\ ${ }^{\mathrm{b}}$ East-Asia: Poverty Reduction and Economic Management Division, the \\ World Bank, 1818 H Street, N.W., Washington, DC 20433, U.S.A.
}

Using the recently developed linearity test and nonlinear unit root test, this study shows that the income gaps of Finland, Norway and Sweden with respect to Denmark are nonlinear but stationary with no significant trend effect, implying the Nordic countries have already attained steady state of income equality, a state beyond catching up as identified earlier in Oxley and Gresley (1999). This fresh evidence strengthens the finding of Nordic Convergence Club by these authors.

\section{Introduction}

The two stages of income convergence - catching-up (narrowing of income gap between two contrasting economies over time) and long-run convergence (the steady state of no income gap) - may be identified via time series stationary tests, see Oxley and Greasley (1995, 1997, 1999). Specifically, the rejection of the null hypothesis in the stationary tests (Dickey-Fuller, Phillips-Perron, etc.) with significant (insignificant) trend implies catching-up (long-run convergence). Notably, previous studies are confined to linear testing frameworks. Lately, the findings of nonlinearity in the income gaps in Liew and Lim (2005) alert us on the urgent need of attention in this area of study. They also demonstrated that linear augmented Dickey-Fuller (ADF) and nonlinear (Kapetanois et al. (2003) (hereafter KSS) tests results can be in sharp contrast, when nonlinearity is present in the income gaps.

In the spirit of Liew and Lim (2005), the current article intends to further explore the usefulness of KSS test in detecting the two stages of income convergence in the Nordic countries (Sweden, Denmark, Finland and Norway), in which evidence of a Nordic Convergence Club consisting of Sweden, Denmark and Finland but not Norway has been provided by Oxley and Greasley (1999).

The remainder of this article is structured as follows: Section II discussed the method for the identification of long-run convergence and catchingup. Section III describes the linearity test. Section IV presents and interprets the estimated results. Concluding remarks are offered in the final section.

\section{Identifying Catching-up and Long-run Convergence}

As usual, one can de-mean and de-trend a given income gap series, $y_{t}=\log Y_{L}-\log Y_{H}$ where $Y_{L}$ and $Y_{H}$ are the real per capital gross domestic products of the relatively poorer and richer economies, respectively, by regressing $y_{t}$ on a constant and a trend terms using the least squares (OLS) method to obtain:

$$
\tilde{y}_{t}=y_{t}-\hat{\alpha}-\hat{\beta} t
$$

where $\tilde{y}_{t}$ is the de-meaned and de-trended $y_{t}$.

*Corresponding author. E-mail: venusliew@ums.edu.my 